\title{
Gestational Hypervolemic Hypertension Is Clinically Different from "Classical" Preeclampsia
}

\author{
Eszter Hantosi ${ }^{1,2 *}$, Zsolt Ifi ${ }^{1}$, Sára Jeges ${ }^{3}$, József Bódis ${ }^{1,2,3}$, Péter Tamás ${ }^{1,2}$ \\ ${ }^{1}$ Department of Obstetrics and Gynecology, University of Pécs, Clinical Center, Pécs, Hungary \\ ${ }^{2}$ The MTA-PTE Human Reproduction Scientific Research Group, Hungarian Academy of Sciences (MTA), \\ Budapest, Hungary \\ ${ }^{3}$ Institute of Nursing and Patient Care, Faculty of Medicine, University of Pécs, Pécs, Hungary \\ Email: ${ }^{*}$ hantosie@freemail.hu
}

Received 5 April 2014; revised 15 May 2014; accepted 8 July 2014

Copyright (C) 2014 by authors and OALib.

This work is licensed under the Creative Commons Attribution International License (CC BY). http://creativecommons.org/licenses/by/4.0/

\section{(c) (i) Open Access}

\begin{abstract}
Objective: Homogenous pathogenesis of preeclampsia has been challenged. We examined the clinical characteristics of preeclamptic patients with discordant fetal growth which is one of the controversial issues in preeclampsia. Methods: Clinical index values including central hemodynamics of third-trimester preeclamptic patients with distinct fetal birth weights (group A: birth weight $\geq 50$ th percentile; $n=23$ and group $B$ : birth weight $<50$ th percentile; $n=14$ ) were compared. Results: Pregnant women of group A were characteristically obese and edematous, but no fetal complications were observed. Patients of group B were younger, onset of preeclampsia was earlier, proteinuria was more severe, and fetal compromise was frequent. A marked difference between the two groups was noticed in central hemodynamics as the mean of Co (cardiac output) was 8.5 and $5.6 \mathrm{l} / \mathrm{min}$ in group $A$ and $B$, respectively $(p<0.001)$. CO of less than $7.451 / \mathrm{min}$ was found to be associated with fetal birth weight below 50th percentile $(O R=15.6 ; 95 \%$ CI: 3.2 and 45.8, $p=0.001$ ). Conclusions: Augmented CO in pregnancy may ensure efficient placental blood supply, but it may cause hypertension with subsequent moderate proteinuria. This condition, however, seems to be different from the "classical" preeclampsia.
\end{abstract}

\section{Keywords}

Preeclampsia, Distinct Birth Weights, Distinct Hemodynamics

Subject Areas: Gynecology \& Obstetrics, Women's Health

*Corresponding author.

How to cite this paper: Hantosi, E., Ifi, Z., Jeges, S., Bódis, J. and Tamás, P. (2014) Gestational Hypervolemic Hypertension Is Clinically Different from "Classical" Preeclampsia. Open Access Library Journal, 1: e751.

http://dx.doi.org/10.4236/oalib.1100751 


\section{Introduction}

Homogeneous pathogenesis of preeclampsia has been challenged mainly by distinct fetal somatic growth in patients with the diagnosis of preeclampsia. The reduced utero-placental blood flow-endothelial cell dysfunction - end-organ damage pathway is reasonably associated with fetal growth restriction [1] [2]. However, the diagnosis of preeclampsia is also associated with high incidence of fetal birth weight above the 90th percentile [3]-[5].

Whether this contradiction in fetal growth is due to the early or late onset of the disease, or is the consequence of a different pathogenesis of gestational hypertension with proteinuria is still being explored.

It was assumed, that the different pathogenesis should also be reflected by distinct clinical courses, when preeclampsia was associated either with decreased or with normal/augmented fetal growth.

\section{Patients and Methods}

Medical records of patients admitted to the Department of Obstetrics and Gynecology, University of Pécs with a diagnosis of preeclampsia throughout a 3-year period were retrospectively reviewed. Preeclampsia was defined according to the Hungarian (identical to the ACOG) classification (blood pressure $\geq 140 / 90 \mathrm{mmHg}$ at least on two occasions, 6 hours apart with proteinuria $\geq 0.3 \mathrm{~g}$ /day after the 20th gestational week).

Index values of clinical courses included maternal weight, age and parity, main characteristics of preeclampsia, central hemodynamics and of fetal well-being.

Hemodynamic monitoring, as the part of institutional routine examinations in preeclampsia was performed by bioimpedance cardiograph (type ICG-M401, ASKIT LTD, Budapest, Hungary) after the 31st week, when CO) already does not show any further increase [6]. The highest values of blood pressure and daily proteinuria recorded during the hospitalization were considered for statistical analysis.

Patients were divided into two study groups according to the Hungarian BW (birth weight) percentile of the neonates: $\mathrm{BW} \geq 5$ th percentile (group $\mathrm{A}, \mathrm{n}=23$ ), and $\mathrm{BW}<50$ th percentile (group $\mathrm{B}, \mathrm{n}=14$ ). Patients with twin gestation, diabetes mellitus, known cardiac or vascular diseases, smokers and those, whose pregnancy had to be terminated before the 31st week, were ineligible for this study.

Statistical analysis was performed by the use of Statistical Package for the Social Sciences (SPSS Inc., Chicago, IL) software for Windows. Inter-group differences of continuous variables were analyzed by Student $t$-test or Mann-Whitney $U$-test; for categorical variables chi-square or Fisher's exact test was used, as appropriate. The association of low BW with the examined variables was estimated by relative risk in terms of OR (odds ratio) obtained from logistic regression analysis; correlations between CO and maternal weight or BMI (body mass index) were assessed by Pearson's test.

\section{Results}

Results show that discordant fetal growth in patients with the diagnosis of preeclampsia was associated with remarkably distinct gestational characteristics (Table 1). Mothers, who delivered newborns with a BW of $\geq 50$ th percentile were older, had later hypertension, and less severe proteinuria, than patients delivering newborns with BW < 50th percentile. Moreover, increased fetal growth was associated with higher maternal weight or BMI, and frequently with maternal edema in accordance with more gestational weight gain. It is of note that oligohydramnios and non-reassuring CTG and/or abnormal Doppler flow velocimetry results occurred only in the group of lower BW. A marked difference between the study groups was noticed in CO, which, by our method was found to be an average of $6.8 \pm 1.3 \mathrm{l} / \mathrm{min}$ (mean $\pm \mathrm{SD}$ ) in normal third-trimester pregnancies [7]. The mean (range) values of gestational ages at hemodynamic examinations were similar: 36.3 (32 - 40) weeks in group A and 35.1 (32 - 38) weeks in group B $(\mathrm{p}=0.051)$. CO of less than $7.45 \mathrm{l} / \mathrm{min}$ has been associated with the increased probability of BW below the average (OR: 15.6; 95\% confidence intervals: 2.3 and 45.8; $\mathrm{p}=0.001$ ). Otherwise no other examined parameter showed correlation to fetal BW.

In addition, considering the whole study population, $\mathrm{CO}$ correlated with maternal body weight $(\mathrm{r}=0.617 ; \mathrm{p}<$ $0.001)$ and also with BMI $(r=0.419, \mathrm{p}=0.01)$.

Because of threatened eclampsia pregnancy had to be terminated at the 26th week in one case.

\section{Discussion}

This study suggests that gestational hypertension with proteinuria may have different pathogenesis since preec- 
Table 1. Clinical characteristics of patients with the diagnosis of preeclampsia and distinct fetal birth weight.

\begin{tabular}{|c|c|c|c|}
\hline & $\begin{array}{c}\text { Birth weight } \\
\geq 50 \text { th percentile } \\
(\mathrm{n}=\mathbf{2 3})\end{array}$ & $\begin{array}{c}\text { Birth weight } \\
<50 \text { th percentile } \\
(n=14)\end{array}$ & $\mathrm{p}$ value \\
\hline Maternal age (years) & $28.4 \pm 1.3$ & $24.6 \pm 0.9$ & 0.046 \\
\hline Nulliparous & $13 / 23$ & $11 / 14$ & NS \\
\hline Onset of hypertension (gestational week) & $35.8 \pm 0.8$ & $31.4 \pm 1.1$ & $<0.001$ \\
\hline Maximum MAP (mmHg) & $117.7 \pm 1.8$ & $123.5 \pm 2.2$ & NS \\
\hline Maximum proteinuria (g/day) & $0.82 \pm 0.12$ & $2.47 \pm 0.58$ & 0.015 \\
\hline $\mathrm{CO}(\mathrm{l} / \mathrm{min})$ & $8.5 \pm 0.3$ & $5.6 \pm 0.4$ & $<0.001$ \\
\hline PVR (dyn $\cdot \mathrm{sec} \cdot \mathrm{cm}^{-5}$ ) & $1041.1 \pm 61.6$ & $1702.1 \pm 167.7$ & 0.002 \\
\hline Body mass index $\left(\mathrm{kg} / \mathrm{m}^{2}\right)$ & $35.8 \pm 1.1$ & $29.6 \pm 1.4$ & 0.001 \\
\hline Weight gain (kg) & $14.7 \pm 1.5$ & $11.0 \pm 1.5$ & NS \\
\hline Oligohydramnios & $0 / 23$ & $10 / 14$ & $<0.001$ \\
\hline Non-reassuring antepartum CTG or abnormal Doppler flow results & $0 / 23$ & $7 / 14$ & $<0.001$ \\
\hline Gestational age at delivery (weeks) & $38.3 \pm 0.4$ & $36.6 \pm 0.6$ & 0.035 \\
\hline
\end{tabular}

Note: Data are given as mean $\pm \mathrm{SE}$ or number of cases.

lamptic pregnancies with normal/augmented or decreased neonatal BW show remarkably different clinical courses, including central hemodynamics.

In the group of fetal BW below the average, the low $\mathrm{CO}$, the severe proteinuria, and the frequent oligohydramnios are in accordance with characteristic features of preeclampsia, such as contracted blood volume, diminished microcirculation, and consequent end-organ damages [1] [8].

In contrast, hemodynamics in group A showed an opposite change. The high CO with low vascular resistance seems to represent a formerly reported hyperdynamic model of preeclampsia [9] [10]. Central hemodynamics suggests that hypertension in group A may be attributed to a relaxed, but overfilled vasculature. The normal or frequently augmented fetal somatic growth suggests an excellent placental blood supply secondary not only to high CO, but probably to hypertension, too [10]. Women in this group were characteristically obese and edematous. Obesity is known to be associated with gestational hypertension or preeclampsia [11]; gestational edema is associated with higher fetal weight [12]. The favorable fetal outcome in hypervolemic cases has already been reported [13].

In this model the obesity and hypertension may play a role in the development of moderate proteinuria [11] [14].

According to Poisseuille-Hagen equation (in simplified form: perfusion or $\mathrm{CO}=$ Pressure/Resistance) hypertension may be the result of not only elevated vascular resistance but also of high CO. Findings of hemodynamic examinations of this study suggest, that in the hypovolemic cases the high resistance, whereas in hypervolemic patients the high blood volume is responsible for hypertension. It is tempting to assume, that the hypovolemic type may correspond with the early-onset preeclampsia, whereas hypervolemic cases could be a subset of lateonset disease with a different pathogenesis [15].

Our data support, that gestational hypertension with proteinuria may develop via distinct pathways and suggest, that gestational hypervolemic hypertension may be different from the "classical" preeclampsia.

Exploring the background of increased water retention in hypervolemic cases may provide a better insight into the pathogenesis of this condition. Precognition of CO in hypertensive pregnant patients may permit more precise pregnancy outcome evaluation, better management strategies, and allow the selection of more homogenous population for clinical studies.

\section{Declarations of Interest}

The author reports no declarations of interest. 


\title{
References
}

[1] Lain, K.Y. and Roberts, J.M. (2002) Contemporary Concepts of the Pathogenesis and Management of Preeclampsia. JAMA, 287, 1383-1386. http://dx.doi.org/10.1001/jama.287.24.3183

[2] Sibai, B.M. (2008) Intergenerational Factor. A Missing Link for Preeclampsia, Fetal Growth Restriction, and Cardiovascular Disease? Hypertension, 51, 993-994. http://dx.doi.org/10.1161/HYPERTENSIONAHA.107.104489

[3] Xiong, X., Demianczuk, N.N., Buekens, P. and Saunders, L.D. (2000) Association of Preeclampsia with High Birth Weight for Age. American Journal of Obstetrics \& Gynecology, 183, 148-155. http://dx.doi.org/10.1016/S0002-9378(00)24793-5

[4] Rasmussen, S. and Irgens, L.M. (2003) Fetal Growth and Body Proportion in Preeclampsia. Obstetrics \& Gynecology, 101, 575-583. http://dx.doi.org/10.1016/S0029-7844(02)03071-5

[5] Vatten, L.J. and Skjaerven, R. (2004) Is Preeclampsia More than One Disease? BJOG, 111, 298-302. http://dx.doi.org/10.1111/j.1471-0528.2004.00071.x

[6] van Oppen, A.C.C., Stigter, R.H. and Bruinse, H.W. (1996) Cardiac Output in Normal Pregnancy: A Critical Review. Obstetrics \& Gynecology, 87, 310-318. http://dx.doi.org/10.1016/0029-7844(95)00348-7

[7] Tamás, P., Szilágyi, A., Jeges, S., Vizer, M., Csermely, T., Ifi, Z., Bálint, A. and Szabó, I. (2007) Effects of Maternal Central Hemodynamics on Fetal Heart Rate Patterns. Acta Obstetricia et Gynecologica Scandinavica, 86, 711-714. http://dx.doi.org/10.1080/00016340701252217

[8] Visser, W. and Wallenburg, H.C.S. (1991) Central Hemodynamic Observations in Untreated Preeclamptic Patients. Hypertension, 17, 1072-1077. http://dx.doi.org/10.1161/01.HYP.17.6.1072

[9] Easterling, T.R. and Benedetti, T.J. (1989) Preeclampsia: A Hyperdynamic Disease Model. American Journal of Obstetrics \& Gynecology, 160, 1447-1453. http://dx.doi.org/10.1016/0002-9378(89)90869-7

[10] Naeye, R.L. (1981) Maternal Blood Pressure and Fetal Growth. American Journal of Obstetrics \& Gynecology, 141, 780-787.

[11] Callaway, L.K., O’Callaghan, M. and McIntyre, H.D. (2009) Obesity and Hypertensive Disorders of Pregnancy. Hypertension in Pregnancy, 28, 473-493. http://dx.doi.org/10.3109/10641950802629626

[12] Dunlop, W., Furness, C. and Hill, L.M. (1978) Maternal Haemoglobin Concentration, Haematocrit and Renal Handling of Urate in Pregnancies Ending in the Births of Small-for-Dates Infants. BJOG, 85, 938-940.

[13] Chaffin, D.G. and Webb, D.G. (2009) Outcomes of Pregnancies at Risk for Hypertensive Complications Managed Using Impedance Cardiography. American Journal of Perinatology, 26, 717-721. http://dx.doi.org/10.1055/s-0029-1223283

[14] Kublickas, M., Lunell, N.-O., Nisell, H. and Westgren, M. (1996) Maternal Renal Artery Blood Flow Velocimetry in Normal and Hypertensive Pregnancies. Acta Obstetricia et Gynecologica Scandinavica, 75, 715-719. http://dx.doi.org/10.3109/00016349609065733

[15] Rolfo, A., Racano, A., Tal, R., Tagliaferro, A., Ietta, F., Wang, J., Post, M. and Caniggia, I. (2010) Abnormalities in Oxygen Sensing Define Early and Late Onset Preeclampsia as Distinct Pathogenesis. PLoS One, 5, e13288.

\author{
Abbreviations \\ BMI: body mass index \\ BW: birth weight \\ CO: cardiac output \\ CTG: cardiotocography \\ MAP: mean arterial pressure (systolic blood pressure $+2 \times$ diastolic blood pressure)/3 \\ OR: odds ratio \\ PVR: peripheral vascular resistance
}

